\title{
ACTA BIOLOGICA
}
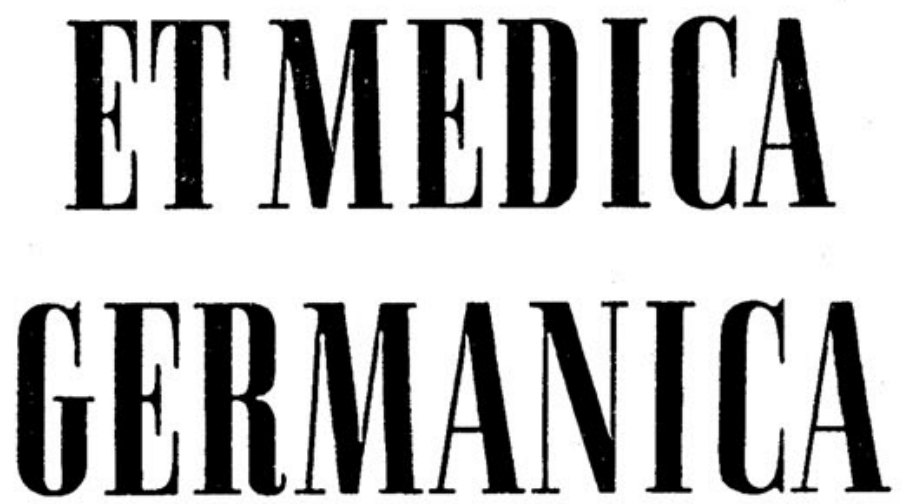

HERAUSGEBER:

R. BAUMANN, H. DUTZ, A. GRAFFI, H. GUMMEL, F. JUNG, L.-H. KETTLER, S. M. RAPOPORT

UNTER MITARBEIT VON:

W. BEIER, H. DRISCHEL, H. FRUNDER, M. GERSCH, E. GOETZE, H. HANSON, F. HAUSCHILD, G. HOLLE, F. MACH, H. MATTHIES, G. MOHNIKE†, O. PROKOP, K. SCHUBERT, F. SCHWARZ,

G. STERBA, A. WOLLENBERGER

SCHRIFTLEIT UNG:

W. SCHELER, H. BIELKA

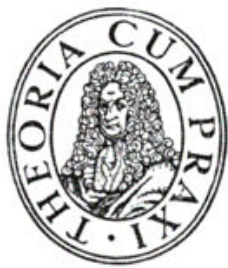

AKADEMIE-VERLAG · BERLIN • BAND 17 • HEFT 4 - SEITE 375-559 • 1966 